\title{
ONTOLOGIA, DESEJO E POLÍ́TICA EM ESPINOSA
}

\author{
Luiz Carlos Montans Braga ${ }^{1}$ \\ Universidade Estadual de Feira de Santana (UEFS) \\ https://orcid.org/0000-0002-6989-1249 \\ E-mail: montansbraga@hotmail.com
}

\section{RESUMO:}

No primeiro movimento o artigo analisa, em panorama, a ontologia espinosana. Após, mostra como, do interior dos conceitos presentes na ontologia, derivam os de homem, desejo, alegria e tristeza, esperança e medo, segurança e desespero, ação e paixão. Da relação entre ontologia, homens e desejo bem como dos demais afetos -, são extraídas, em breves considerações, algumas teses políticas de Espinosa. Levanta-se, neste movimento argumentativo, a hipótese de que as teses políticas espinosanas derivam de sua ontologia e de sua concepção de homem como desejo e variação de potência. $\mathrm{O}$ conceito de desejo é analisado à luz da variação de potência e do tema do direito natural, o qual, em Espinosa, se identifica a potência. Quando das breves derivações à política, algumas teses hobbesianas - relacionadas aos temas da multidão, povo, representação, direito natural, estado civil, etc. - são trazidas à argumentação para que se mostre, por contraste, o peso das inovações espinosanas.

PALAVRAS-CHAVE: Ontologia; Desejo; Política; Espinosa.

\section{ONTOLOGY, DESIRE AND POLITICS IN SPINOZA}

\begin{abstract}
:
First of all, the article analyzes, in panorama, Spinoza's ontology. Secondly, it shows how, from the concepts present in the ontology, the author derives others, as man, desire, joy and sorrow, hope and fear, security and despair, action and passion. From the relationship between ontology, men and desire - as well as from the other affects -, are extracted, in brief considerations, some Spinoza's political thesis. In this argumentative movement, the hypothesis is that many Spinoza's political thesis arise from its ontology and its conception of man as desire and potency variation. The concept of desire is analyzed in the light of the variation of potency and the theme of natural right, which in Spinoza is identical to potency. When the subject is the brief derivations to politics, some hobbesian thesis - related to the following subjects, namely, the multitude, the people, the representation, the natural right, the civil state, etc. - are brought to show, by contrast, the importance of Spinoza's innovations.
\end{abstract}

KEYWORDS: Ontology; Desire; Politics; Spinoza.

\footnotetext{
${ }^{1}$ Doutor em Filosofia pela Pontifícia Universidade Católica de São Paulo (PUCSP), São Paulo - SP, Brasil. Professor da Universidade Estadual de Feira de Santana (UEFS), Feira de Santana - BA, Brasil.
}

BRAGA, Luiz Carlos Montans Ontologia, Desejo e política em Espinosa. Griot : Revista de Filosofia, AmargosaBA, v.19, n.1, p.139-158, fevereiro, 2019. 


\begin{abstract}
"Estou inteiramente espantado, inteiramente encantado! Tenho um precursor e que precursor! Eu não conhecia quase nada de Espinosa; que eu agora ansiasse por ele foi uma "ação do instinto". Não só, que sua tendência geral seja idêntica à minha - fazer do conhecimento o afeto mais potente - em cinco pontos capitais de sua doutrina eu me reencontro, este pensador, o mais fora da norma e o mais solitário, me é o mais próximo justamente nestas coisas: ele nega o livre-arbítrio -; os fins -; a ordem moral do mundo -; o não-egoísmo-; o mal -; [...] In summa: minha solidão, que, como sobre montes muito altos, com frequência provocou-me falta de ar e fez-me o sangue refluir, é ao menos agora uma dualidão. Maravilhoso!" (Carta sobre Espinosa - Nietzsche) ${ }^{2}$

“- Ah! eu nunca entendi de política; nunca me meti nessas cousas.

- Tudo pode ser política, minha senhora; uma anedota, um dito, qualquer cousa de nada, pode valer muito." (Casa Velha - Machado de Assis) ${ }^{3}$
\end{abstract}

\title{
Pano de fundo ontológico em panorama
}

Espinosa, por longa data, foi lembrado mais por seu modo geométrico de escrita (a Ética é o exemplo mais claro e distinto) e pela identificação entre os conceitos de Deus, natureza e substância que por suas teses especificamente éticas e políticas. Muita tinta foi gasta no intuito de provar que, para Espinosa ${ }^{4}$, não haveria qualquer ética ou política possíveis. A razão seria simples. Ao identificar a substância (Deus, ou seja, a natureza) ao real, positividade infinita e absolutamente potente, causa sui, que opera por uma necessidade imanente (E I P 11, p. 59; E I P 14, p. 67 e sgtes; E I P 15, p. 67 e sgtes $)^{5}$, de um lado, e, de outro, ao conceber os homens como modificações finitas dessa mesma realidade, coisas singulares, intensidades de potência advindas da potência absolutamente infinita (E I Def. 5, p. 44; E II P 7, p. 127; entre outras), tais interpretações não vislumbraram, em uma filosofia dessa natureza, qual poderia ser o campo de ação de cada homem (ética) muito menos o lugar da política.

Espinosa usa a forma retórica para os escólios e apêndices da Ética. Nesses movimentos de raciocínio, o intento é o melhor convencimento do leitor. Para os leitores contemporâneos, não habituados aos fios secos e densos da geometria, os escólios e apêndices são oásis em meio à sistematicidade cerrada dos demais

\footnotetext{
2 NIETZSCHE, 2007, p. 137.

3 ASSIS, 1986, p. 04.

${ }^{4}$ As obras de Espinosa que serão citadas se encontram na edição crítica de Carl Gebhardt (ESPINOSA. 1972). As traduções citadas são as seguintes: Para a Ética, ESPINOSA, 2015. A paginação indicada é a desta edição. Foi consultada também a tradução de Tomaz Tadeu que, quando citada, será indicada (ESPINOSA, 2008). Quanto ao Tratado Político (TP), ESPINOSA, 2009. Quanto ao Tratado Teológico-político (TTP), ESPINOSA, 2003. Quanto à Correspondência (Ep), ESPINOSA, 1988. Para a E e o TP, usar-se-á a seguinte abreviação: para a Ética E, seguido da parte em romano, D para definições, Def af para definição dos afetos, A para axiomas, Dem para demonstrações, P para proposições, Cor para corolários, Ap para apêndices, L para lemas, Esc para escólios, Post para postulados, Explic para explicações. Um numeral arábico indicará o número de cada um desses itens. Após, a página em arábico. Para o TP, numeral romano indica o capítulo e numeral arábico indica o parágrafo. Após, a página em arábico. Para o TTP, numeral romano indica o capítulo. Após, a página em arábico. Para a Correspondência, Ep, com página em arábico. Edições indicadas nas Referências bibliográficas. Embora não se cumpra, assim, estritamente, as regras da ABNT, adota-se este modo de citação para facilitar a consulta a qualquer edição das obras de Espinosa. Desse modo se cumpre a ABNT quanto ao espírito da regra.

${ }^{5}$ Mais precisamente, a ontologia espinosana se apresenta em toda a parte I da Ética (pp. 44-121).
} 
momentos do texto. No Apêndice da parte I, há um excerto em que Espinosa explica com linguagem límpida o que havia demonstrado no correr dos axiomas, definições, proposições e demonstrações da parte I acerca do conceito de Deus. Escreve:

Com isto, expliquei a natureza de Deus e suas propriedades, tais como: que existe necessariamente; que é único; que é e age pela só necessidade de sua natureza; que é causa livre de todas as coisas e como o é; que tudo é em Deus e depende dele de tal maneira que sem ele nada pode ser nem ser concebido; e, finalmente, que tudo foi predeterminado por Deus [quòd omnia à Deo fuerint praedeterminata], não decerto pela liberdade da vontade, ou seja, por absoluto beneplácito, mas pela natureza absoluta de Deus, ou seja, por sua potência infinita. (E I Ap, p. 109).

Em uma filosofia do necessitarismo - tudo decorre da rede causal, nada havendo sem causa e tudo operando por estrita necessidade da imanência da substância -, na qual há uma, e apenas uma, substância, causa de si e de tudo o que há ${ }^{6}$ que espécie de liberdade seria possível aos homens compreendidos como modificações finitas dessa mesma substância? ${ }^{7}$ Ora, caberia aos homens, em uma filosofia dessa natureza, ou seja, panteísta, na qual tudo é Deus e na qual tudo é necessário, contentarem-se com a condição de epifenômenos da potência infinita.

Muito provavelmente duas fontes autorais de peso, entre outras de mesma linhagem, e suas respectivas interpretações da obra de Espinosa foram as responsáveis pela predominância desse olhar em face das teses espinosanas, sobrepondo-se, como imagem, ao que o filósofo propôs conceitualmente em suas obras. Duas ou três palavras sobre estes autores, a seguir, apenas para pontuar este dado histórico significativo, uma vez que responsável por certa compreensão do espinosismo que, de fato, eclipsou o "Espinosa de Espinosa" na história da filosofia.

Um é Pierre Bayle, autor do verbete Spinoza (BAYLE, 1696), no qual o Holandês é apresentado como um ateu de sistema, de difícil refutação. Ateu de sistema uma vez que levou ao limite o projeto do ateísmo especulativo, uma espécie de racionalismo insensato levado às últimas consequências (CHAUI, 2009, p. 318) ${ }^{8}$. Nesse sentido, propunha em sua obra a tese de um Deus material, equivalente ao real, identificado à natureza, uma única substância da qual os homens seriam meras modificações do pensamento e da extensão. Em suma, um panteísta, pois tudo é Deus e Deus está em tudo, nada havendo nem podendo ser concebido fora dele. Ora, um panteísta é um ateu uma vez que concebe um Deus que não é Deus, pois o Deus proposto é de natureza tal que não corresponde ao conceito que a tradição lhe atribui, seja bíblica, seja filosófica. É como se Espinosa houvesse concebido um círculo quadrado, isto é, um absurdo conceitual. Daí a acusação de uso insensato da razão. E seria um ateu de sistema precisamente por seu método geométrico, uma

\footnotetext{
${ }^{6}$ Ver, para esses temas em Espinosa: E I P 7 p. 53; E I P 8, p. 53; E I P 11, p. 59; E I P 15, p. 67; E I P 18, p. 83; E I P 26, p. 91; E I P 28, p. 93; E I p 29, p. 95.

7 Acerca da possibilidade da realidade efetiva dos modos, refutando a tese de que seriam epifenômenos de Deus, ver: DELEUZE, 1968. Especialmente $3^{\text {a }}$ parte, pp. 179-181.

8 Para a questão das tradições interpretativas do espinosismo, suas gêneses, desdobramentos e influências, consultar: CHAUI, 1999, pp. 113-321.
}

BRAGA, Luiz Carlos Montans. Ontologia, Desejo e política em Espinosa. Griot : Revista de Filosofia, Amargosa BA, v.19, n.1, p.139-158, fevereiro, 2019. 
forma de amarrar de maneira quase irrefutável seus absurdos conceituais, levando ao limite da aporia o racionalismo moderno9 ${ }^{9}$

Morfino propõe, nessa mesma linha de um Espinosa sombreado pela imagem que dele se fez, a influência de Hegel. Com efeito, como poderia haver qualquer filosofia da ação (uma ética), ou qualquer filosofia política, que demandam conceitos como o de liberdade de ação por parte dos homens, na história, em uma filosofia da eternidade, sem temporalidade? (MORFINO, 2012, pp. 16-17)

No entanto, Espinosa escreveu uma Ética e dois tratados sobre política (Tratado Teológico-político e Tratado Político). Como explicar este aparente paradoxo?

Ao tratar do funcionamento do desejo, pela via do texto da Ética, talvez seja possível mostrar, com algum grau de precisão, como as leituras da obra de Espinosa foram antes leituras exteriores ao seu texto. Ou melhor, em razão de Espinosa reformular por completo muitos dos conceitos com os quais operava - realizando a tarefa máxima da filosofia, de colocar em xeque a tradição e os conceitos vigentes -, todo o seu sistema deve ser lido por dentro, sem que se recorra a teses externas. Ao reformular o conceito de substância (única, e não dupla, como em Descartes), e conceber o homem como modificação da substância, os conceitos éticos e políticos, que operam no interior da substância, tomam outra tonalidade.

\section{Homem, desejo: qual relação?}

Na proposição 10 da parte II, Espinosa afirma que à essência do homem não pertence o ser da substância (E II P 10, p. 141). De fato, isso seria absurdo, uma vez que a substância é eterna e infinita, é o real em sua autoprodução. O homem, portanto, não poderia ser uma substância. E conclui, na mesma proposição, que a substância não constitui a forma do homem. O que seria o homem? O corolário da mesma proposição responde, em parte, à questão, resposta cujo complemento se dá na demonstração. Afirma Espinosa: "Daí segue que a essência do homem é constituída por modificações certas dos atributos de Deus." (E II P 10, p. 141). Na demonstração, conclui: "O ser da substância [...] não pertence à essência do homem. Esta, portanto [...], é algo que é em Deus e que sem Deus não pode ser nem ser concebido, ou seja [...], uma afecção, ou seja, um modo que exprime a natureza de Deus de maneira certa e determinada." (E II P 10 cor e dem, p. 143). O homem é afecção, é modo, é modificação da substância, não é uma substância (pensante e extensa, como em Descartes). Espinosa opera com o mesmo termo da tradição, mas o reconceitualiza, adequando-o ao seu sistema. Em E II P 11 (pp. 145-147), bem como

\footnotetext{
9 Ver, acerca do verbete de Bayle e de sua influência, CHAUI, 2009, pp. 313-314. Afirma a autora: "Para os estudiosos da filosofia espinosana, o verbete Spinoza do Dictionnaire é de grande relevância histórica, pois, com Bayle, nasce propriamente a tradição interpretativa do espinosismo. São dele ideias, imagens e sugestões que iriam alimentar, durante os séculos vindouros, as sucessivas leituras da obra e, mais frequentemente, as substituíram, o verbete sendo mais lido do que Espinosa." (p. 313). E, ainda: "Nele [...] consolida-se a imagem do perigo espinosista, isto é, de uma razão que não conhece limites, cuja hybris a faz descambar no paradoxo e na incoerência. Essa imagem que, em Bayle e na sua posteridade imediata, cristaliza-se na figura do "ateu de sistema", irá, mais adiante, com a laicização do augustinismo, do calvinismo e do jansenismo [...], levar ao aparecimento do problema do espinosismo, isto é, a impossibilidade de uma ética da liberdade numa filosofia que expulsa a finalidade e afirma a necessidade absoluta, problema enfaticamente posto por Jacobi na "querela do panteísmo", retomado com obstinação por Kant e jamais abandonado depois dele." (p. 314).
} 
na respectiva demonstração e corolário, define o primeiro modo da substância da qual o homem é expressão finita, a saber, o pensamento. Na proposição 13, Espinosa indicará o outro modo do qual o homem é expressão finita, a saber, a extensão. Afirma na E II P 13 (p. 149) que "O objeto da ideia que constitui a Mente humana é o Corpo, ou seja, um modo certo da Extensão, existente em ato, e nada outro." Para daí concluir, no corolário da mesma proposição, que "Daí segue que o homem consta de Mente e Corpo, e que o Corpo humano existe tal como o sentimos." (E II P 13, cor, p. 149).

Portanto, o homem é modo finito da substância no seguinte sentido: modificação do atributo pensamento, modificação do atributo extensão, ambos expressões da substância única. De acordo com a proposição 7 de E II, que afirma que "A ordem e conexão das ideias é a mesma que a ordem e conexão das coisas", conclui Espinosa que tudo que se passa no corpo de um homem corresponde a uma ideia em sua mente. Por exemplo, a ideia do próprio corpo, ou mesmo a ideia de um corpo externo, de outro modo finito. Assim, o corpo humano existe tal como o sentimos, e os demais corpos do mundo também existem tal como os sentimos, tais como se apresentam, na forma de afecções do corpo e ideias dessas afecções na mente. Espinosa apresenta aqui, de maneira incipiente, o conceito de afeto, que define como segue: "Por afeto entendo as afecções do Corpo pelas quais a potência de agir do próprio Corpo é aumentada ou diminuída, favorecida ou coibida, e simultaneamente as ideias destas afecções." (E III def. 3, p. 237).

É preciso, como afirma Deleuze ${ }^{10}$, dar crédito ao filósofo quando este usa dois termos distintos sem os considerar sinônimos. É o caso aqui. De um lado, afeto, de outro, afecção. $O$ afeto é uma transição de potência do modo, para mais ou para menos, para uma maior ou menor intensidade. E esta variação é função das afecções que se apresentam ao modo, e no que aqui interessa, aos homens. Por exemplo, um homem, Pedro, é afetado pelo encontro com outro, Paulo. Pedro passa a ter uma imagem de Paulo em sua mente, advinda da afecção. E isso decorre de como Paulo se fez afecção em Pedro. Uma afecção visual, eventualmente tátil, etc., que simultaneamente veio a ser imagem de Paulo na mente de Pedro. Isto é a afecção, sua definição, sua natureza. $O$ que decorre dela, a variação de potência advinda deste encontro, é afeto. Portanto o afeto é a variação de potência do corpo, e por conseguinte da mente, decorrente da afecção, ou das afecções, vivenciadas pelo indivíduo. No caso de Pedro, o encontro com Paulo fez deste uma afecção em Pedro (e uma imagem em sua mente, simultaneamente), a qual gerou neste um sentimento, um afeto, isto é, uma variação de potência.

Como o homem é modificação finita da mente da substância, bem como da extensão, é intensidade de potência, porém finita. É, como muitas outras coisas na natureza (na substância, em Deus), coisa singular. No axioma da parte IV, a condição das coisas singulares é definida de maneira clara como potência finita entre potências finitas. Afirma Espinosa: “Na natureza das coisas, não é dada nenhuma coisa singular tal que não se dê outra mais potente e mais forte do que ela. Mas, dada

${ }^{10}$ DELEUZE, 1981, pp. 68-72, para a diferença entre os conceitos de afecção e afeto. Tradução em: DELEUZE, 2002. Sobre a diferença entre afecção e afeto, nesta edição, pp. 55-58.

BRAGA, Luiz Carlos Montans. Ontologia, Desejo e política em Espinosa. Griot : Revista de Filosofia, Amargosa BA, v.19, n.1, p.139-158, fevereiro, 2019. 
uma coisa qualquer, é dada uma coisa mais potente pela qual aquela pode ser destruída." (E IV Ax, p. 381).

Os homens - cada um deles, cada indivíduo, assim como os demais modos da substância - são este esforço (conatus) da mente e do corpo para perseverar. Espinosa define esta condição das coisas nas proposições 6, 7 e 8 da parte III da Ética, e as fundamenta na tese de que não poderia ser diferente, visto serem modificações da potência que as alimenta para serem o que são, isto é, modificações da e na substância. Em E III P 6 (p. 251) a tese se apresenta cristalina: "Cada coisa [o homem é uma coisa singular, como um cão, uma árvore, um inseto, etc.], o quanto está em suas forças [quantum in se est], esforça-se para perseverar em seu ser [in suo esse perseverare conatur]." E a proposição 7 conclui: "O esforço [conatus] pelo qual cada coisa de esforça para perseverar em seu ser [in suo esse perseverare conatur] não é nada além da essência atual da própria coisa."

Todos esses conceitos serão concatenados por Espinosa no escólio da proposição 9 da parte III. E ali se chega a uma excelente definição de homem no interior mesmo da ontologia espinosana, amarrando-o ao conceito de desejo, que interessa a este artigo.

A proposição 9 da referida parte trata da mente. Afirma que "A Mente [...] esforça-se [conatur] para perseverar em seu ser por uma duração indefinida e é cônscia deste seu esforço." O escólio acrescenta alguns conceitos, e apresenta uma definição do que seja a essência do homem. Diz:

Este esforço, quando referido à só Mente, chama-se Vontade [Voluntas]; mas quando é referido simultaneamente à Mente e ao Corpo chama-se Apetite [Appetitus], que portanto nada é outro que a própria essência do

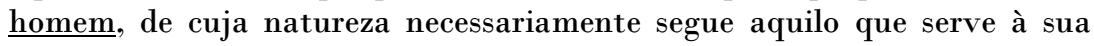
conservação; e por isso o homem é determinado a fazê-lo. Em seguida, entre apetite e desejo [cupiditas] não há nenhuma diferença senão que o desejo é geralmente referido aos homens enquanto são cônscios de seu apetite, e por isso pode ser assim definido: o Desejo é o apetite quando dele se tem consciência. De tudo isso, constata-se então que não nos esforçamos, queremos, apetecemos, nem desejamos nada porque o julgamos bom; ao contrário, julgamos que algo é bom porque nos esforçamos por ele, o queremos, apetecemos e desejamos. (E III P 9 esc, pp. 253-255 - grifo meu).

Duas partes, dois movimentos, compõem este escólio. Na primeira, Espinosa define a essência do homem como desejo, e iguala este conceito, de um ponto de vista real, ontológico, ao de apetite. A diferença entre apetite e desejo é, segundo o filósofo, apenas que ao desejo se acrescenta a consciência que se tem do apetite. A vontade é definida, por sua vez, como o esforço da mente apenas. Mas este esforço da mente não se dá sem o esforço simultâneo do corpo (E II P 7, p. 135), portanto as diferenças entre estes termos, para Espinosa, são apenas conceituais. O que importa é a definição do homem como esforço da mente e do corpo, portanto desejo de perseverar, esforço este cuja duração é indefinida. Pelo axioma da parte IV, tem-se que este esforço é indefinido uma vez que a destruição da coisa singular apenas se dá por outra, mais potente ( $\mathrm{E}$ IV ax, p. 381). Apresenta-se aqui a tese de um campo de forças (potências) que se dá tanto entre humanos, quanto entre estes e as demais

BRAGA, Luiz Carlos Montans. Ontologia, Desejo e política em Espinosa. Griot : Revista de Filosofia, Amargosa - 
coisas singulares existentes na realidade. Chave maquiaveliana ${ }^{11} \mathrm{com}$ refinamento ontológico cerrado? Tema para outros artigos ${ }^{12}$.

O escólio da proposição 11 poderá dar o arremate à questão do homem como desejo. De fato, nela Espinosa mostra o desejo, acima definido como a própria essência do homem, como um dos três afetos primários, sendo os outros dois a alegria e a tristeza, os quais são, na verdade, variações de intensidade, para mais ou para menos, do próprio desejo em função das afecções. Ficará claro, com a análise do escólio, a costura que o autor propõe entre o conceito de homem como potência, afeto como transição e desejo como variação da intensidade da potência para mais (alegria) ou para menos (tristeza), isto é, a própria essência do homem na existência. O que se pode adiantar, em relação a Maquiavel, neste ponto da argumentação tema para outros artigos -, é o fato de que Espinosa trabalha com o conceito de força (potência) como fundamento de sua argumentação acerca do homem. De fato, a definição de afeto utiliza o conceito de potência: "Por Afeto entendo as afecções do Corpo pelas quais a potência de agir do próprio Corpo é aumentada ou diminuída, favorecida ou coibida, [...]." (E III Def 3, p. 237). Entretanto, o grau de refinamento ontológico espinosano certamente não se encontra em Maquiavel - e pode-se colocar em discussão a existência de teoria explícita acerca da ontologia no florentino ${ }^{13}$. Por outro lado, na Ética ao menos, nada se extrai dos exemplos históricos diferentemente do Tratado Teológico-político -, o que em Maquiavel é fonte primária para as teses políticas. Isso possibilita um apontamento: se o refinamento ontológico de Espinosa para definir o homem como desejo não se encontra em Maquiavel, isto não traz como consequência que suas construções políticas sejam distantes. Uma hipótese é que isto ocorra exatamente pela tese de fundo presente em ambos: a do campo de forças ou potências se sobrepondo a qualquer formalismo ilusório, ou utopia, para a definição da política, de seu campo, de suas buscas institucionais por segurança e paz.

Em suma, ao que indicam os textos - apenas para desdobrar minimamente este fio da semelhança entre ambos -, ambos trabalham com a mesma chave conceitual geral, a da luta entre potências, a do campo de forças, para o trato do que virá a ser, para cada um, o conjunto de soluções políticas. Portanto, desse ponto de vista, ambos se assemelham muito e Espinosa bem pode ter bebido conceitos em Maquiavel, para além das citações explícitas. Isto o que Morfino (2012, p. 98) definiu como sendo o esqueleto maquiaveliano presente no Tratado Político, que não casualmente, portanto, teria presente teses de Maquiavel desde o início (TP I 1, pp. 05-06) até o último parágrafo dos capítulos propriamente teóricos, ou seja, até TP V 7 (p. 46), momento em que Maquiavel é chamado acutissimus. As teses de Maquiavel estariam presentes, segundo o mesmo comentador, igualmente no Tratado Teológico-

\footnotetext{
11 Sobre a questão do campo de forças, comum a ambos, ver: LUCCHESE, 2009. A parte I do livro é dedicada ao tema do realismo em ambos. A parte II é dedicada ao tema do conflito social e político em Maquiavel e Espinosa. O tema do conflito, para Lucchese, é chave para que se compreenda a modernidade de Espinosa e Maquiavel no sentido do que apresentam como pensamento da contracorrente, isto é, na verdade, ambos caminham na contramão das teses da modernidade (p. 04).

12 As pesquisas sobre as confluências entre ambos estão em andamento.

${ }^{13}$ Lucchese, entretanto, levanta a tese da existência de uma ontologia em Maquiavel. LUCCHESE, 2009, p. 04. Escreve: "As características do realismo de Maquiavel e de Espinosa podem bem ser definidas começando por suas ontologias."
}

BRAGA, Luiz Carlos Montans. Ontologia, Desejo e política em Espinosa. Griot : Revista de Filosofia, Amargosa BA, v.19, n.1, p.139-158, fevereiro, 2019. 
político, ainda que matizadas pelo fato de que Espinosa, nesta obra, adotaria ainda, em algum grau, conceitos contratualistas (MORFINO, 2012, pp. 67-98).

Retorna-se, após este breve desvio ao tema da política, a Espinosa e à Ética para findar a análise do conceito de desejo e mostrar sua relação estreita com os demais afetos, todos derivados da alegria e da tristeza, e com o conceito de potência (de força, isto é, direito - uma vez que jus sive potentia - TP II 5, p. 12).

De volta ao escólio da proposição 11 da Ética III. No caput da proposição, Espinosa propõe que o que quer que aumente, ou diminua, a potência do corpo, aumenta ou diminui a potência da mente. Esse aumento ou diminuição de potência do corpo e da mente explicam, de acordo com o escólio, os afetos de alegria e tristeza. Escreve Espinosa:

\begin{abstract}
Assim, por Alegria, entenderei na sequência a paixão pela qual a Mente passa a uma maior perfeição. Por Tristeza, a paixão pela qual ela passa a uma menor perfeição. [...] Ademais, o que seja o Desejo, expliquei no escólio da Proposição 9 desta parte, e não reconheço nenhum outro afeto primário além destes três, pois mostrarei na sequência que os restantes se originam deles. (E III P 11 esc, pp. 255-257).
\end{abstract}

Com os excertos acima, tem-se uma definição do homem como desejo e uma explicação acerca do seu funcionamento. Antes de analisar todos esses conceitos em conjunto, mais um trecho da Ética facilitará a compreensão do conceito de desejo. Nas definições dos afetos, Espinosa escreve: "O Desejo é a própria essência do homem enquanto é concebida determinada a fazer [agir] algo por uma dada afecção sua qualquer." (E III Def Af I, p. 339). Como alinhavar estas definições?

Primeiro passo: o homem é intensidade de potência na medida em que é modificação da substância, esta eterna e infinita e absolutamente potente. $O$ homem é modificação de dois dos infinitos atributos de Deus, a saber, o pensamento e a extensão. Não se tratará aqui da densa questão dos atributos e da razão pela qual são infinitos, cada um em seu gênero, e ao mesmo tempo constituintes da substância única - um aparente paradoxo. Trata-se de tema importante, mas que foge aos propósitos do presente artigo. Em razão de o homem ser potência, esforça-se por perseverar em seu ser. Tal esforço (conatus) é o exercício do apetite. Como entre apetite e desejo Espinosa não explicita nenhuma diferença, exceto por ser o desejo o apetite do qual se tem consciência, tal esforço é o desejo (E III P 9 esc, pp. 253-255). Fica claro, por seu turno, pelo escólio da proposição 11, acima citada, que este é um dos afetos primários. $\mathrm{O}$ esforço ou desejo transita para um estado de perfeição maior, alegria, ou para um estado de perfeição menor, tristeza. Esta transição é o que Espinosa chama afeto, como já analisado. A transição se dá em função das afecções que o corpo recebe. Elas podem gerar transição para mais potência, isto é, alegria, ou para menos potência, isto é, tristeza. Como todos os afetos são variações desses dois (alegria ou tristeza), a vida afetiva dos homens está compreendida nesta transição de potência que é, na verdade, transição de alegria à tristeza e vice-versa, aumento e diminuição de potência na duração.

Há ainda alguns fios a serem unidos neste rol de raciocínios. Espinosa usa o termo perfeição. Por quê? Em razão de sua ontologia. No escólio da proposição X da parte I, o autor define Deus, ou seja, a substância única, como a completa perfeição

BRAGA, Luiz Carlos Montans. Ontologia, Desejo e política em Espinosa. Griot : Revista de Filosofia, Amargosa BA, v.19, n.1, p.139-158, fevereiro, 2019. 
ou realidade, precisamente por ser constituída por infinitos atributos, os quais exprimem sua infinita e eterna potência e sua infinita e eterna realidade, causa imanente de todo o real. Na definição 6 da parte II, Espinosa define perfeição como sendo o mesmo que realidade - portanto, é o mesmo que potência, pois a realidade da substância, considerada de seu próprio "ponto de vista", é a potência como realidade total ou perfeição como realidade total. Afirma: "Por realidade e perfeição entendo o mesmo." (E II def 6, p. 127). Esta definição está presente, com os mesmos contornos, no Tratado político (TP II 3-4, p. 12). 0 motivo deste desvio ontológico é explicar a alegria e a tristeza como aumento ou diminuição de perfeição, como definido no escólio acima citado. Afirma o escólio: “Assim, por Alegria, entenderei na sequência a paixão pela qual a Mente passa a uma maior perfeição. Por Tristeza, a paixão pela qual ela passa a uma menor perfeição." (E III P 11 esc, p.257). Fica cristalina, portanto, a relação entre desejo como variação de potência, alegria como transição do desejo para maior realidade ou potência, e a tristeza como diminuição do desejo para menos realidade ou potência. Ademais, todos esses conceitos, que se referem ao homem, têm ligação com os conceitos especificamente ontológicos de Espinosa, pois os homens são modificações da substância única - são expressões finitas da intensidade de potência de dois de seus atributos, a saber, o pensamento e a extensão.

Donde se pode compreender com mais precisão a definição I dos afetos: "O Desejo é a própria essência do homem enquanto é concebida determinada a fazer [agir] algo por uma dada afecção sua qualquer." (E III Def Af I, p. 339). Isto é, o homem - seu desejo - transita da alegria à tristeza e vice-versa em função das afecções que passam a constituir sua essência. Por isso o autor concluirá, na explicação desta definição:

Portanto, entendo aqui pelo nome de Desejo [Cupiditas] quaisquer esforços [conatus], ímpetos [impetûs], apetites [appetitûs] e volições [volitiones] de um homem que, segundo a variável constituição do mesmo homem, são variáveis e não raro tão opostos uns aos outros que ele é arrastado de diversas maneiras e não sabe para onde voltar-se. (E III def af I explic, p. 339).

Um tema que se liga fortemente ao do desejo é o da diferença, proposta por Espinosa, entre ação e paixão. Ao definir afeto, na parte III, este tema é apresentado como parte da definição. Ei-la novamente, agora com o adendo:

Por afeto entendo as afecções do Corpo pelas quais a potência de agir do próprio Corpo é aumentada ou diminuída, favorecida ou coibida, e simultaneamente as ideias destas afecções. Assim, se podemos ser causa adequada de alguma destas afecções, então por Afeto entendo ação; caso contrário, paixão. (E III def. 3, p. 237 - o itálico é do original, mantido pelos tradutores).

Espinosa estabelece a seguinte diagramação dos afetos. De um lado, há os afetos passivos, que podem ser alegres, quando há um encontro que aumenta a potência do homem, ou tristes, quando há encontro que a diminui. De outro, há os afetos ativos, que são decorrentes de ações (alegria). Os afetos ativos são sempre ações, geram sempre alegria. Uma ação se dá quando um indivíduo é capaz de ser causa adequada, forjando um afeto alegre, por meio do conhecimento adequado do 
que é bom. Não será aprofundado este ponto, importante, é certo, mas que, neste momento, representaria um desvio longo em face do tema principal deste artigo. Para mostrar que não se trata de algo meramente geométrico - e isso é importante ser frisado -, recorre-se a um exemplo de Deleuze (2009, p. 44), a saber, a ingestão de arsênico. Se se conhecem os efeitos do arsênico em um corpo, sabe-se que não será um bom encontro aquele entre o veneno e o corpo, pois ele ocasionará a decomposição da estrutura deste indivíduo, deste modo finito, desta coisa singular. Assim, a não ingestão, o evitar este encontro, decorre de um conhecimento adequado do que é bom ao desejo, pois a ingestão representaria a anulação mesma do desejo, uma vez que o corpo morreria, converter-se-ia em outra estrutura individual que não a desta coisa singular. O raciocínio vale para qualquer coisa singular humana. Desse modo, aquela precisa constituição individual, aquele homem, deixaria de perseverar na existência pela potência do veneno ingerido e seus efeitos no corpo. Uma ação, nesse caso, significa um conhecimento acerca desse mau encontro e o evitar do mau encontro. Eis um afeto alegre decorrente de uma ação. Nada há de comum entre o arsênico e o corpo humano a ponto de sua ingestão ser causa de aumento de potência. $\mathrm{O}$ corpo do homem não compõe com o arsênico. Ao invés, sua ingestão é causa da decomposição do corpo. Por sua vez, é possível um conhecimento adequado que gera uma ação. $O$ exemplo é o do encontro entre uma onda e um indivíduo, um homem. Quando o encontro entre uma onda e o corpo não leva à anulação, mas à composição, tem-se o conhecimento adequado a operar e a gerar uma ação ou afeto ativo alegre. Novamente o exemplo é de Deleuze (2009, p. 241). Se o homem encontra a onda e não sabe com ela compor, não sabe nadar, ele tem seu corpo anulado, ele morre. $O$ conhecimento inadequado do que há de comum entre a onda e o corpo leva a que a onda destrua o corpo, aquele indivíduo. Porém, quando este homem sabe nadar, sabe compor com a onda, ambos formam um todo mais amplo, um indivíduo mais amplo. Eis um exemplo do homem como causa adequada, o que é uma ação ou um afeto alegre ativo, com o consequente aumento de potência.

Os dois postulados que vêm logo a seguir à definição III, de afeto, auxiliam na compreensão das teses espinosanas. Escreve o autor: "O Corpo humano pode ser afetado de muitas maneiras pelas quais sua potência de agir é aumentada ou diminuída, e também de outras que não tornam sua potência de agir nem maior nem menor." (E III Post I, p. 237). E complementa: “O Corpo humano pode padecer muitas mudanças, retendo, contudo, as impressões ou vestígios dos objetos [...] e, consequentemente, as mesmas imagens das coisas; [...]." (E III Post II, pp. 237-239).

Portanto, o homem pode ser afetado de múltiplas formas, experienciar muitas afecções, as quais farão que a essência mesma do homem, seu desejo, varie para mais ou para menos. Há outras que lhe são indiferentes. $\mathrm{O}$ surdo é indiferente à música $(\mathrm{E}$ IV Pref, p. 377). Entretanto, pode ser afetado pela visão de alguém de quem não gosta. A imagem desse alguém é para ele uma afecção, a qual gera um afeto de tristeza, uma transição para menos potência. $O$ postulado II, acima citado, introduz um tema de fundamental importância para o caminho do desejo de cada homem no mundo. As afecções, que são impressões, formam imagens, as quais são afecções que, por sua vez, levam a afetos, a transições de potência. A memória terá papel importante para cada indivíduo e seu desejo, visto que as experiências passadas, as imagens que elas deixam no corpo, podem ser acessadas pela memória e podem 
definir o melhor caminho a ser tomado pelo desejo. No exemplo acima dado, do surdo, ele apenas sabe que não gosta de alguém que viu porque pode acessar, pela memória, uma afecção gerada por este alguém que diminuiu sua potência. A memória é tema definido por Espinosa na proposição 18 da parte II. Afirma o autor que "Se o Corpo humano tiver sido afetado uma vez por dois ou mais corpos em simultâneo, quando depois a Mente imaginar um deles, imediatamente se recordará dos outros." (E II P 18, p. 169). No escólio desta proposição, afirmará que "Daqui claramente entendemos o que seja a Memória. Com efeito, não é nada outro que alguma concatenação de ideias que envolvem a natureza das coisas que estão fora do Corpo humano, a qual ocorre na Mente segundo a ordem e a concatenação das afecções do corpo humano." (E II P 18 esc, pp. 169-170). No mesmo escólio, o autor mostrará que este modo de concatenar ideias é função da experiência de afecções de cada indivíduo humano no passado. Um soldado, ao ter acesso a vestígios de um cavalo, a partir do pensamento acerca do cavalo terá imediatamente o pensamento sobre o cavaleiro e a seguir sobre a guerra e assim sucessivamente. Por seu turno, o camponês, ao ter acesso aos mesmos vestígios e ao pensamento acerca do cavalo que daí advirá, pensará em sequência no arado, no campo, etc. (E II P 18 esc, p. 171). Assim, concluirá Espinosa, "cada um, conforme costumou juntar e concatenar as imagens das coisas desta ou daquela maneira, a partir de um pensamento incidirá em tal ou tal outro." (E II P 18 esc, p. 171). Ou seja, a memória é a concatenação das afecções, e demanda, para cada um, suas vivências e sua história. E, por ser concatenação de imagens-afecções, gera afetos, transições de potência, a cada vez que um homem tem acesso, pela via desse mecanismo, às imagens-afecções.

Mais um ponto a ser salientado a partir destas considerações é o fato de que o critério do bom e do mau, por ser função do desejo, não depende de qualquer heteronomia, de qualquer moral, de qualquer padrão exterior ao desejo que seja metro da sua boa ou má conduta. $O$ metro da boa ação é o desejo. Recapitula-se o final de uma das passagens acima analisadas para dar o arremate à questão do desejo em Espinosa.

Trata-se do seguinte excerto, definitivo para o tema da ética e da política. Escreve Espinosa: "De tudo isso, constata-se então que não nos esforçamos, queremos, apetecemos, nem desejamos nada porque o julgamos bom; ao contrário, julgamos que algo é bom porque nos esforçamos por ele, o queremos, apetecemos e desejamos." (E III P 9 esc, p. 255). Portanto, o metro da ética espinosana é o desejo, sua procura por situações que o levem ao aumento de sua potência e a fuga daquelas que a diminuam. Para isso a memória terá papel importante, pois será também por ela que o desejo poderá evitar os maus encontros e cultivar os bons. Define, com efeito, Espinosa, que a causa do que é bom é o que o desejo define como tal, aquilo para o quê ele se esforça. É bom o que o desejo busca, isto é, uma coisa é boa porque o desejo a busca. E é má porque o desejo a evita. $O$ que é bastante diferente de outro critério, a saber, o do metro exterior a indicar ao desejo o que ele deve buscar, marca por excelência de uma ética heterônoma, em que regras exteriores definem o que deve ser bom e ruim e o padrão a medir as ações é sempre externo. Neste último caso, a causa da boa ação é exterior, é porque a coisa é julgada boa que o desejo a deve buscar: eis o sentido inverso do que Espinosa propõe; esta a ética heterônoma que Espinosa combate com suas teses.

BRAGA, Luiz Carlos Montans. Ontologia, Desejo e política em Espinosa. Griot : Revista de Filosofia, Amargosa BA, v.19, n.1, p.139-158, fevereiro, 2019. 


\section{Breves derivações à política}

Estas reviravoltas no campo da ética e no seu respectivo conceito de desejo têm consequências para a política, pois há um desvio em face das utopias de toda espécie - e nesse ponto, novamente, vê-se presente, ainda que tacitamente, Maquiavel e sua busca da realidade efetiva da coisa em vez daquilo que se imagina acerca dela [Ma sendo l'intenzione mia stata scrivere cosa che sia utile a chi la intende, mi è parso piú conveniente andare dreto alla verità effettuale della cosa che ala immaginazione di essa] (P XV, p. 151) ${ }^{14}$. De fato, como assinala Espinosa na Carta 50 , o que o distancia de Hobbes é que este pensa o direito natural alienado ao soberano desde o momento do pacto, restando ao súdito, como espécie de resquício de potência, a defesa do direito à vida no caso limite de o soberano a colocar em risco. Isto é, o direito natural, para Hobbes, é próprio ao estado de natureza. Findo este, constituído o estado civil por meio do pacto, aliena-se à instância soberana o direito de dizer o direito. $\mathrm{O}$ que resta do direito natural é apenas a possibilidade de o súdito defender sua vida em caso de o poder soberano intentar retirá-la.

Refina-se, a seguir, um pouco mais esta tese. Desse modo, poder-seá ter mais precisão na compreensão do contraponto representado pelo campo conceitual espinosano. Há, pois, um abismo a separar as teses de um campo e de outro.

Em Hobbes, com efeito, a paz, como ausência de guerra, advém da transferência do direito natural de cada membro do corpo político a um poder comum, cuja única maneira de ser instituído é, como afirma o autor no Leviatã, a via do pacto:

[...] conferir toda sua força e poder [de cada homem] a um homem, ou a uma assembleia de homens, que possa reduzir suas diversas vontades, por pluralidade de votos, a uma só vontade. $O$ que equivale a dizer: designar um homem, ou uma assembleia de homens como representante de suas pessoas [...], todos submetendo assim suas vontades à vontade do representante, e suas decisões a sua decisão. (Leviatã II 17 p. 144) ${ }^{15}$.

Conclui Hobbes que isso é "[...] uma verdadeira unidade de todos eles, numa só e mesma pessoa, realizada por um pacto de cada homem com todos os homens, [...]" (Leviatã II 17 p. 144).

Em Do Cidadão, obra anterior ao Leviatã, o formalismo hobbesiano mostra todo seu peso no momento em que o autor inglês diferencia povo de multidão. Neste ponto, fica clara a distância entre o campo conceitual espinosano, de um lado, e o campo do formalismo jurídico-político de Hobbes, de outro. Neste passo da argumentação de Hobbes, apresenta-se um dos mais interessantes e curiosos paradoxos a que as teses do filósofo inglês o encaminham, a saber, o povo só é um, e se constitui como tal, quando transfere poder à assembleia ou ao rei. Antes disso, é

\footnotetext{
${ }^{14}$ Há outra versão em italiano, que é a seguinte: "Ma sendo l'intento mio scrivere cosa utile a chi la intende, mi è parso più conveniente andare drietto alla verità effettuale della cosa, che alla immaginazione di essa." (MAQUIAVEL, 1961, p. 55). Para as citações de O Príncipe, romano para o capítulo e arábico para a página. Edição de citação: MAQUIAVEL, 2011.

${ }^{15}$ A paginação é a da Coleção Os Pensadores, citada ao final, nas Referências bibliográficas. Parte em romano e capítulo em arábico.
}

BRAGA, Luiz Carlos Montans. Ontologia, Desejo e política em Espinosa. Griot : Revista de Filosofia, Amargosa BA, v.19, n.1, p.139-158, fevereiro, 2019. 
dispersão, conceito que Hobbes estabelece como sinônimo de multidão, a qual não pode ser capaz de ação por não ter sido unificada em forma de povo, pela transferência do direito natural ou à assembleia, ou ao rei. Em suma, ao um. No caso da transferência dos direitos naturais ao um da monarquia, o rei passa a ser sinônimo de povo, pois os direitos naturais de cada indivíduo, antes dispersos em forma de multidão, foram transferidos ao que os unifica. No caso da monarquia, o rei.

Assim, no parágrafo oitavo do Capítulo 12 do De Cive, Hobbes trata da sedição, tema geral do referido Capítulo, ao explicitar a diferença entre multidão e povo $^{16}$. Para Hobbes, o povo pode ser definido como uno, tendo uma só vontade. A definição de povo em Hobbes é, pois, explicitamente formal. Como aparece de modo mais claro em passagens do Leviatã, o conceito de representação é que dá o tom dessa formalidade. Quando cada indivíduo, em estado de natureza, transfere, para sua futura paz e segurança, ao um ou à assembleia de homens, seus direitos, este um ou esta assembleia passam a ser o povo. $O$ povo é uno na medida em que está representado pelo um, ou pela assembleia. A vontade de qualquer desses (um ou assembleia) é a vontade do povo, pois o um, ou a assembleia, está presente em-lugarde (é re-presentante neste sentido político do termo). Por isso a vontade passa a ser uma, pois o povo é uno, e a ele, povo, nesse sentido e nesta situação, pode-se atribuir uma ação. A multidão, por seu turno, para Hobbes, é sinônimo de dispersão, própria do estado de natureza, das vontades individuais em luta.

Vê-se com clareza a enorme distância em face de Espinosa, que colocará, no Tratado político, a multidão como fundamento do imperium e dos direitos por este instituídos. Não há, pois, em Espinosa, qualquer dispersão impeditiva do caráter político da multidão, muito menos qualquer conceito que vise à sua unificação por meio de definições formais, como é o caso em Hobbes.

Por meio do mecanismo de transferência de direitos naturais da multidão ao rei, poderá Hobbes afirmar, no caso de uma monarquia, flertando com o paradoxo, que o rei é o povo. Escreverá, pela mesma lógica, que em uma democracia ou aristocracia o povo é a assembleia que governa. Com efeito, afirma:

\begin{abstract}
Em último lugar, constitui um grande perigo para o governo civil, em especial o monárquico, que não se faça suficiente distinção entre o que é um povo e o que é uma multidão. O povo é uno, tendo uma só vontade, e a ele pode atribuir-se uma ação; mas nada disso se pode dizer de uma multidão. Em qualquer governo é o povo quem governa. Pois até nas monarquias é o povo quem manda (porque nesse caso o povo diz sua vontade através da vontade de um homem), ao passo que a multidão é o mesmo que os cidadãos, isto é, que os súditos. Numa democracia e numa aristocracia, os cidadãos são a multidão, mas o povo é a assembleia governante (the court). E numa monarquia os súditos são a multidão, e (embora isso pareça um paradoxo) o rei é o povo. (HOBBES, 2002, p. 190)
\end{abstract}

Com base nesses mecanismos formais de transferência de direitos, Hobbes afirma que qualquer contestação à autoridade suprema poderá ser chamada de lesamajestade, pois um ataque à majestade suprema é um ataque àqueles ou àquele que detém o poder, ou, ainda mais precisamente, que está investido do poder transferido

${ }^{16}$ Segundo Renato Janine Ribeiro, na nota 5 ao Capítulo, Hobbes institui a distinção entre ambos os conceitos com mais precisão neste momento em face dos demais passos da obra (HOBBES, 2002, p. 385).

BRAGA, Luiz Carlos Montans. Ontologia, Desejo e política em Espinosa. Griot : Revista de Filosofia, Amargosa BA, v.19, n.1, p.139-158, fevereiro, 2019. 
pela multidão no pacto originário. George Orwell levou ao requinte este princípio no livro '1984' (ORWELL, 2009) ${ }^{17}$, momento em que a instância de poder poderia, no limite, saber de todos os atos dos membros do corpo político pela constante e precisa vigilância de cada passo dos súditos e pelo apagamento sistemático de qualquer história ou memória de resistência ao poder instituído.

Portanto, em suma, Hobbes, em chave bastante diversa da proposta na via espinosana, estabelece um conceito de direito natural que, mesmo sendo potência, após o pacto se esfumaça e se transmuta em formalismo vazio. Esfumaça-se o direito natural no sentido de que deixa de ser potência de cada indivíduo para ser potência concentrada nas mãos do poder soberano. Em outras palavras, a transferência do direito natural, pelo pacto, justifica a potência concentrada seja nas mãos da assembleia, seja nas mãos do monarca. $O$ direito de resistir, se há algum após o pacto, apenas poderá ser exercido no caso de a vida do súdito estar sob ameaça explícita do soberano. Assim, do direito natural originário resta este mínimo circunstancial. Posição, portanto, muito diversa da espinosana.

Uma hipótese que poderia ser desdobrada em pesquisas futuras é a seguinte: muito do formalismo do direito contemporâneo, bem como das instituições políticas operantes nos países democráticos, têm como uma das fontes as elaborações formalistas de Hobbes e suas soluções conceituais ao problema da dispersão da multidão.

Para Espinosa, em vez disso - e este o ponto central da carta 50 a Jelles -, o direito natural é a pedra de toque do estado civil. No sistema espinosano, com efeito, o direito natural é mantido no estado civil (Ep. 50, p. 398). Afirma a carta, em seu primeiro movimento, no qual a questão do direito natural e da diferença entre as filosofias políticas de Hobbes e Espinosa é o tema:

Você me pergunta qual a diferença entre a concepção política de Hobbes e a minha. Ela consiste em que mantenho sempre o direito natural e que considero que o magistrado supremo, em qualquer cidade, só tem direitos sobre os súditos na medida em que seu poder seja superior ao deles; coisa que sempre ocorre no estado natural. (Ep. 50, p. 398) ${ }^{18}$

\footnotetext{
17 No Capítulo 13 do De Cive, Hobbes propõe a tese de que a Commonwealth deva ter espiões/espias por todo seu espaço de atuação, antecipando o que Orwell desenhou com requinte e uso da técnica no seu '1984'. A ideia é, com base no conceito de prevenção, a commonwealth se organizar tendo seus ouvidos espalhados, capilarizados pela república. A metáfora que Hobbes usa, explicitando um mecanismo para evitar e prevenir o dano ao corpo político, é a da teia de aranha. Esta, no cento de sua teia, sabe o que ocorre em toda a longa extensão dos fios. Dado o menor movimento, ela o sente e se previne. Hobbes pensa o caráter preventivo nos termos dessa metáfora. Conclui que quem exerce o poder não sabe o que é necessário enviar para a defesa dos súditos se não tiver espias, tal qual a aranha só sabe o que ocorre pelos fios de sua teia [Espias como Spies na ed. de H. Warrender - "They who bear Rule can no more know what is necessary to be commanded for the defence of their Subjects without Spies, then those Spiders can when they shall goe forth, and whether they shall repair, without the motion of those threds." (HOBBES, 1983, p. 159)]. O trocadilho spies/spiders se perde na tradução. Na edição da Martins Fontes, o texto foi assim traduzido: "Quem exerce o poder não pode saber o que é necessário mandar para a defesa dos súditos se não tiver espias [Spies], da mesma forma que sem o movimento de seus fios essas aranhas (spiders) não podem saber quando devem sair, nem se devem consertar." (HOBBES. 2002, p. 201 - a palavra Spies, entre colchetes, não consta desta tradução, ao passo que spiders, entre parênteses, sim).

${ }^{18}$ Para a tradução, cotejou-se o original latino com a tradução de Marilena Chaui, presente no volume da coleção Os Pensadores (ESPINOSA, 1973), bem como com a tradução de Atilano Dominguez (ESPINOSA, 1988). A página é a da edição ESPINOSA, 1973.
}

BRAGA, Luiz Carlos Montans. Ontologia, Desejo e política em Espinosa. Griot : Revista de Filosofia, Amargosa BA, v.19, n.1, p.139-158, fevereiro, 2019. 
Qual a relação, pois, entre a manutenção do direito natural na cidade, o desejo e a potência dos homens? ${ }^{19} \mathrm{Na}$ argumentação desenvolvida até o momento, procurou-se mostrar, pelas passagens da Ética, que o desejo é variação de potência, como se depreende dos excertos acima analisados. Quando variação para mais potência, é alegria. Quando variação para menos potência, é tristeza. Como todos os demais afetos derivam destes três, quatro deles são especialmente importantes para a cidade, para o estado civil. Trata-se da esperança e do medo e outros dois deles derivados, a saber, a segurança e o desespero"2. A esperança define-se assim: "A Esperança é a Alegria inconstante originada da ideia de uma coisa futura ou passada de cuja ocorrência até certo ponto duvidamos." (E III Def af 12, p.347). O medo, por seu turno, assim se define: "O Medo é a Tristeza inconstante originada da ideia de uma coisa futura ou passada de cuja ocorrência até certo ponto duvidamos." (E III Def af 13, p.347). A segurança, por sua vez, é uma alegria “originada da ideia de uma coisa futura ou passada da qual foi suprimida a causa de duvidar." (E III Def af 14, p.347). O desespero, por sua vez, obedece ao mesmo mecanismo, e é uma tristeza "originada da ideia de uma coisa futura ou passada da qual foi suprimida a causa de duvidar." (E III Def af 15, p.347). Desse modo, conclui,

[...] da Esperança se origina a Segurança e do Medo o Desespero quando é suprimida a causa de duvidar da ocorrência da coisa, o que ocorre porque o homem imagina que a coisa passada ou futura está presente e a contempla como tal; ou então porque imagina outras que excluem a existência daquelas coisas que o colocavam em dúvida." (E III Def af 15 Explic, p. $347)$.

Assim, os homens experienciam os afetos spes-metus e securitas-desperatio como variações do desejo, para mais ou para menos, para alegria ou para tristeza, em função das afecções-imagens que têm do futuro ou do passado e da dúvida, presente ou ausente.

Todo este movimento é bastante dinâmico e prático na filosofia espinosana, justificando o terreno do texto, uma Ética, com consequências para a política, como o Tratado político o atesta ao tratar do tema dos afetos em vários momentos. Alguém aguarda a decisão acerca de uma lei que será socialmente benéfica (no entendimento de grande parte dos homens que compõem a cidade). Está-se entre a esperança da aprovação e o medo da não aprovação. Paira a dúvida, e a potência dos homens,

\footnotetext{
19 Tratou-se desta questão, bem mais profundamente, com outro viés, em: MONTANS BRAGA, 2016, pp. 247293. Para o tema da paz e do direito natural em Espinosa, ver: ANDRADE, 2001. Ver, igualmente: AURÉLIO, 2000, p. 157. Afirma Aurélio: "No plano, enfim, da política, justifica não só a identificação do direito natural de cada um com o respectivo poder de agir, mas também a formação da comunidade como um processo que é condição e não restrição para a liberdade individual, na medida em que exponencia a potência de cada um pela associação com os demais e estabiliza a defesa e a independência perante o exterior." (p. 157). Ver, também, sobre o tema: CAMPOS, 2008.

${ }^{20}$ Tratou-se deste tema com minúcia em: MONTANS BRAGA, 2016, pp. 91-113 e pp. 172-215. Sobre a trama dos afetos, tema importante para a política em Espinosa, e especialmente para a questão dos afetos medoesperança e segurança-desespero, ver: CAMPOS, 2008, pp. 289-292. Os afetos esperança e medo aparecem, segundo o autor, geminados para a produção do comum. Alexandre Matheron talvez tenha sido o primeiro comentador a tratar com seriedade a tese da relação estreita entre política e afetos em Espinosa. Ver: MATHERON, 1988. Afirma: "Ora, qual deve ser o ponto de partida de uma gênese do Estado onde intervêm apenas as relações de força de indivíduos passionais? Somente pode ser a teoria das relações inter-humanas passionais." (p. 320).
}

BRAGA, Luiz Carlos Montans. Ontologia, Desejo e política em Espinosa. Griot : Revista de Filosofia, Amargosa BA, v.19, n.1, p.139-158, fevereiro, 2019. 
individualmente - e coletivamente por imitação ou por sentirem o mesmo afeto em face do mesmo fato -, varia incessantemente, enquanto a dúvida permanece, entre estes dois polos de aumento e diminuição. Varia, assim, entre spes e metus, ou seja, entre estas duas manifestações da alegria e da tristeza. Aprovada a lei, a esperança vem a ser segurança, pois a dúvida cessou. Não aprovada, o medo vem a ser desespero.

Tais afetos (seja por meio da imitação afetiva, ou por sentirem vários homens o mesmo afeto em face do mesmo fato simultaneamente ${ }^{21}$ ) são a variação do direito natural dos homens na duração, pela definição mesma de afeto (E III Def 3, p. 237).

Todos estes afetos - medo, esperança, desespero, segurança - são variações do desejo e, portanto, da potência dos homens, pela definição mesma de afeto como variação de potência. Ocorre que potência é sinônimo de direito natural para Espinosa. Com efeito, escreve:

\begin{abstract}
A partir [...] daqui [...] entendemos facilmente o que é o direito de natureza. [...] uma vez que Deus tem direito a tudo e que o direito de Deus não é senão a própria potência de Deus na medida em que se considera esta como absolutamente livre, segue-se daqui que qualquer coisa natural [e os homens são coisas naturais e são modificações de Deus, ou seja, modificações da e na substância, como já visto] tem por natureza tanto direito quanta potência para existir e operar tiver, pois a potência de cada coisa natural, pela qual ela existe e opera, não é outra senão a própria potência de Deus [...]. (TP II 3, p. 12).
\end{abstract}

O mesmo raciocínio está em TP II 5, momento em que Espinosa mostra que as variações da potência do indivíduo se dão em razão dos apetites pelos quais são determinados a agir (TP II 5, pp. 12-13; G III p. 277). Não é pela razão, em geral, que agem, mas pelo desejo cego, determinado pelas afecções dos encontros (TP II 5, p. 12).

\title{
Conclusão
}

O salto qualitativo das teses ontológico-políticas de Espinosa - que reverbera até os tempos atuais - está em manter esta definição de direito natural no estado civil. Ele se distancia de Hobbes, como apontado na Carta 50, pois mantém o direito natural no estado civil. Sendo o direito natural o mesmo que variação da potência do desejo para mais ou para menos, vê-se facilmente que o giro ético acima indicado acerca do desejo tem um enorme peso político, do qual derivam muitas consequências para a cidade e a qualidade do direito natural que deve ser possibilitado pelas instituições nela presentes.

De fato, se o metro da ética é o desejo, sendo bom o que o desejo busca, aquilo para o quê ele se esforça (E III P 9 esc, p. 255), é certo que haverá consequências para as teses políticas. A política se construirá em torno deste conceito de desejo que é metro da ação. ${ }^{21}$ Trabalha-se esta questão com mais profundidade em: MONTANS BRAGA, 2016, pp. 191-227. Ver, sobre o
tema: AURÉLIO, 2000, p. 268. No mesmo sentido: MATHERON, 1988, p. 09, p. 327. 
Para fazer uma suma do argumento ${ }^{22}$, há uma reviravolta completa do campo teórico da política. Este é um fio que pode ser puxado da trama que se desenha desde o início do Tratado político, momento em que Espinosa faz a crítica dos filósofos que concebem os afetos como vícios (TP I 1, p. 5). De fato, não sendo os afetos vícios, mas coisas naturais, variações de potência de cada homem, e portanto do direito natural, a razão de ser da cidade nunca poderá se fundar à revelia desta realidade efetiva. Caso se funde em uma concepção de homem como experienciando afetos que são vícios, todo o desenho do que deva ser a cidade, o estado civil, dirá Espinosa, pode ser compreendido como utopia ou quimera. Trata-se de política que, por não ir às coisas como são, isto é, os homens como afetivos e os afetos como coisas naturais, nunca poderá "ser posta em aplicação, mas [será] sim política que é tida por quimera ou que só poderia instituir-se na utopia ou naquele século de ouro dos poetas [...]" (TP I 1, p. 5).

Espinosa procurará conceber sua filosofia política sempre tendo como fundamento esta concepção de desejo que é o critério do bom. Isto é, uma coisa é boa porque - eis a causa - o homem a deseja, ou seja, ele não a deseja porque ela é boa. A causa do que é bom ou mau não é exterior ao desejo; o desejo é o critério, pois é a causa, do que possa ser concebido por bom ou mau (E III P 9 esc, p. 255).

Desse modo, a cidade deverá ser o locus de instituições que garantam o bom aos desejos. O bom, por não ser exterior ao desejo, é aumento de sua potência. Portanto, tudo que aumente a potência dos desejos dos homens que fundam e mantêm a cidade será bom. Tudo que diminua esta potência, será ruim. Se aumento de potência é o mesmo que alegria, a cidade que forjar instituições que garantam uma maior frequência de alegrias experienciadas pelos súditos-cidadãos tanto mais terá alcançado a finalidade de ter sido concebida.

Uma série de conceitos mais complexos é utilizada por Espinosa para tratar do tema da política - além dos afetos acima indicados, os temas do direito civil como direito natural coletivo, da multidão, do imperium, bem como outros a estes correlatos, como a imitação dos afetos, os limites ao detentor do poder soberano, a democracia como o mais natural dos regimes, etc. Todos estes temas são apresentados e alinhavados em partes da Ética, no Tratado Teológico-político e, por fim, no Tratado político ${ }^{23}$. Uma análise em detalhe destes temas fugiria em demasia do problema mais central do artigo ${ }^{24}$.

Esta costura conceitual, cujo primeiro passo foi acima analisado - puxando da Ética o fio da ontologia, ligando-o ao de homem como desejo e, por fim, a alguns conceitos da política-, pode-se dizer agora com mais elementos, está expressa no início do Tratado político, como apontado e analisado no decorrer deste artigo. Trata-se, com efeito, da consequência necessária de uma gama de definições acerca

\footnotetext{
22 Para desdobramento do tema, ver: MONTANS BRAGA, 2016.

${ }^{23}$ Estas relações são tratadas com mais profundidade em: MONTANS BRAGA, 2016. Contemporaneamente, Antonio Negri e Michael Hardt se apropriam dos conceitos espinosanos para traçarem suas próprias linhas teóricas. Tais conceitos estão espraiados pela obra do italiano (nas de sua autoria exclusiva, bem como nas obras escritas com Hardt). Podem ser encontrados, por exemplo, em: NEGRI \& HARDT, 2001; NEGRI \& HARDT, 2005.

${ }^{24}$ Todos estes temas estão bastante desenvolvidos em: MONTANS BRAGA, 2016. Para o tema deste artigo, procurou-se mostrar apenas algumas ligações entre a ontologia, o desejo como variação de potência (sinônimo de direito natural) e a política, segundo Espinosa.
}

BRAGA, Luiz Carlos Montans. Ontologia, Desejo e política em Espinosa. Griot : Revista de Filosofia, Amargosa BA, v.19, n.1, p.139-158, fevereiro, 2019. 
da ontologia, do desejo e do homem que fazem que a filosofia política daí derivada não possa desaguar em utopias ou quimeras.

Em suma, pode-se afirmar que os temas ontológicos espinosanos deságuam em seu conceito de homem como desejo e em suas elaborações políticas. 


\section{Referências}

ANDRADE, Fernando Dias. Pax Spinozana: direito natural e direito justo em Espinosa. Tese apresentada ao Departamento de Filosofia da FFLCH-USP. São Paulo: 2001.

ASSIS, Machado de. Casa Velha. Rio de janeiro: ed. Paz e Terra, 1986. Disponível em: http://www.dominiopublico.gov.br/download/texto/bv000168.pdf. Acesso: 04 JAN 2019.

AURÉLIO, Diogo Pires. Imaginação e Poder: Estudo sobre a Filosofia Política de Espinosa. Lisboa: edições Colibri, 2000.

BAYLE, Pierre. Dictionnaire historique et critique. Article Spinoza. Disponível em: http://www.spinozaetnous.org/telechargements/Commentaires/Bayle/Bayle_Spinoza. pdf. Acesso: 15 DEZ 2017 [1696].

CAMPOS, André Santos. Ius sive potentia. Individuação jurídico-política na filosofia de Spinoza. Tese apresentada ao Departamento de Filosofia da Faculdade de Letras da Universidade de Lisboa. Lisboa, 2008.

CHAUI, Marilena. A nervura do real: imanência e liberdade em Espinosa. Vol. I: Imanência. São Paulo: Companhia das Letras, 1999.

CHAUI, Marilena. “A estrutura retórica do verbete Spinoza”. In: Kriterion, n. 120, Dez/ 2009, pp. 313-334.

DELEUZE, Gilles. Spinoza et le problème de l'expression. Paris: Les éditions de Minuit, 1968.

DELEUZE, Gilles. Spinoza - Philosophie Pratique. Paris: Les Éditions de Minuit, 1981.

DELEUZE, Gilles. Espinosa: Filosofia prática. Tradução Daniel Lins e Fabien Pascal Lins. São Paulo: ed. Escuta, 2002.

DELEUZE, Gilles. Cursos sobre Spinoza (Vincennes, 1978-1981). Seleção e Introdução de Emanuel A. R. Fragoso e Hélio R. C. Júnior. Tradução Emanuel A.R. Fragoso; Francisca E. B. de Castro, Hélio R. C. Júnior, Jefferson A. de Aquino. Fortaleza: ed. UECE, 2009.

ESPINOSA. Spinoza Opera. Ed. de Carl Gebhardt. Heidelberg: Carl Winter, 4 vols, 1972 [1 $1^{\mathrm{a}}$ ed. 1925].

ESPINOSA. Correspondência [edição parcial da correspondência]. Tradução de Marilena Chaui. Coleção Os Pensadores. São Paulo: Abril Cultural, 1973.

ESPINOSA. Correspondencia. Introducción, traducción, notas e índices de Atilano Domínguez. Madrid: Aliança editorial, 1988.

ESPINOSA. Ética. Tradução de Tomaz Tadeu. Edição bilíngue (Latim-Português). Belo Horizonte: Autêntica, 2008.

ESPINOSA. Ética. Tradução do Grupo de Estudos Espinosanos, da FFLCH USP. Edição bilíngue (Latim-Português). São Paulo: ed. EDUSP, 2015.

ESPINOSA. Tratado Teológico-político. Tradução, introdução e notas de Diogo Pires Aurélio. São Paulo: Martins Fontes, 2003.

ESPINOSA. Tratado Político. Tradução, introdução e notas de Diogo Pires Aurélio. São Paulo: M. Fontes, 2009. 
HOBBES. Leviatã ou matéria, forma e poder de um Estado Eclesiástico e Civil. Tradução de João Paulo Monteiro e Maria Beatriz Nizza da Silva. Coleção Os Pensadores. São Paulo: Abril Cultural, 1997.

HOBBES. Do Cidadão. São Paulo: Martins Fontes, 2002.

HOBBES. De Cive. Edição de Howard Warrender. Oxford: Oxford University Press, 1983.

LUCCHESE, Filippo Del. Conflict, Power, and Multitude in Machiavelli and Spinoza: tumult and indignation. New York/London: ed. Continuum, 2009.

MAQUIAVEL. O Príncipe. Edição bilíngue. Tradução de José Antônio Martins. São Paulo: ed. Hedra, 2011.

MAQUIAVEL. Il Principe. A cura de Luigi Firpo. Torino: Einaudi, 1961. Disponível em: http://www.letteraturaitaliana.net/pdf/Volume_4/t324.pdf. Acesso: 04 JAN 2019.

MATHERON, Alexandre. Individu et communauté chez Spinoza. Paris: Les Éditions de Minuit, 1988.

MONTANS BRAGA, Luiz Carlos. Trama afetiva da política: uma leitura da filosofia de Espinosa. Curitiba: ed. Prismas, 2016.

MORFINO, Vittorio. Le Temps et l'Occasion: la rencontre Spinoza-Machiavel. Tradução de Lucile Langlois e Maxime Giglio. Paris: Garnier, 2012.

NEGRI, Antonio; HARDT, Michael. Império. Rio de Janeiro: ed. Record, 2001.

NEGRI, Antonio; HARDT, Michael. Multidão: guerra e democracia na era do império. Rio de Janeiro: ed. Record, 2005.

NIETZSCHE, F. "Carta sobre Espinosa". Tradução e introdução de Homero Santiago. In: Cadernos Espinosanos 16. São Paulo, FFLCH USP, 2007, pp. 131-137, p. 137.

ORWELL, George. 1984. Tradução de Alexandre Hubner e Heloisa Jahn. São Paulo: Companhia das Letras, 2009.

Autor(a) para correspondência: Luiz Carlos Montans Braga, Universidade Estadual de Feira de Santana, Avenida transnordestina, novo horizonte, 44036336, Feira de Santana - BA, Brasil. montansbraga@hotmail.com 